\title{
Role of the Renal Sympathetic Nerves in the
}

\section{Development and Maintenance of}

\section{Hypertension in the Spontaneously Hypertensive Rat}

\author{
Sherry R. Winternitz, Richard E. Katholi, and SuZanne Oparil, Cardiovascular \\ Research and Training Center and Department of Medicine, Cardiology Division, \\ University of Alabama Medical Center, Birmingham, Alabama 35294
}

A B S T R A C T Neurogenic factors and, in particular, enhanced renal sympathetic tone, have been implicated in the pathogenesis of hypertension in the spontaneously hypertensive rat of the Okamoto strain. To examine the hypothesis that the renal sympathetic nerves contribute to the development and maintenance of hypertension by causing urinary sodium retention, 7-wk-old (early hypertensive) and 18-wk-old (established hypertensive) male spontaneously hypertensive rats were subjected to bilateral renal denervation and compared with sham-operated controls. In 7-wk-old animals renal denervation delayed the onset and slowed the rate of development of hypertension. These alterations were associated with a significantly greater fractional excretion of sodium (percentage of sodium intake excreted) during the first $3 \mathrm{wk}$ after denervation. Blood pressure $2 \mathrm{wk}$ after surgery was $169 \pm 3.5$ (sham) vs. $150 \pm 2.4 \mathrm{~mm} \mathrm{Hg}$ (denervated) $(P<0.001)$, corresponding to fractional sodium excretions of $65 \pm 1.3 \%$ (sham) vs. $80 \pm 2.3 \%$ (denervated) $(P<0.001)$. By the 5 th wk after surgery, at which time an increase in renal norepinephrine content of denervated animals suggested reinnervation, blood pressures in the two groups converged (sham, 199 $\pm 6.5 \mathrm{~mm} \mathrm{Hg}$ vs. denervated $180 \pm 3.5 \mathrm{~mm} \mathrm{Hg}$, NS) and there was no difference in sodium excretion (sham, $77 \pm 2.5 \%$ vs. denervated $79 \pm 2.3 \%$ ). Plasma and kidney renin activity of denervated animals did not differ significantly from that of sham-operated controls. In 18 -wk-old rats renal denervation did not alter blood pressure or urinary sodium excretion. These data indicate that the renal sympathetic nerves contribute to the development of hypertension in the spontaneously hypertensive rat in

Dr. Winternitz is the recipient of a National Heart, Lung, and Blood Clinical Investigator Award (1-K08 HL00707-01). Address reprint requests to Dr. Winternitz.

Received for publication 18 February 1980 and in revised form 14 July 1980. part by causing enhanced sodium retention. Once hypertension is established the renal nerves do not play a significant role in the maintenance of increased blood pressure.

\section{INTRODUCTION}

Although still a matter of controversy, information gained from studies performed in many laboratories suggests that the sympathetic nervous system plays an important role in the development of hypertension in the spontaneously hypertensive rat $(\mathrm{SHR})^{1}$ of the Okamoto strain. Direct measurements of pre- and postganglionic sympathetic nerve activity in both anesthetized and conscious SHR have shown nerve traffic to be increased in comparison to similar measurements in normotensive Wistar Kyoto (WKY) controls (1-3). In addition, the demonstration that brainstem and hypothalamic concentrations of catecholamines and catecholamine synthesizing enzymes of the SHR differ from those of control WKY implicates the central nervous system in the pathogenesis of hypertension in this model $(4,5)$. Further, treatment with both central and peripheral sympatholytic agents has been shown to delay and attenuate the development of hypertension in the $\operatorname{SHR}(6,7)$.

Of particular interest is the importance of the renal sympathetic nerves in the development of hypertension in the SHR. In one study, efferent renal sympathetic activity in the SHR was found to be twice that measured in control WKY rats (8). In addition, experiments performed in three separate laboratories have demonstrated that renal denervation delays the development of hypertension in young SHR $(9-11)$. The mechanisms involved were not elucidated in these studies. As renal sympathetic activity has been shown

${ }^{1}$ Abbreviations used in this paper: SHR, spontaneously hypertensive rat; WKY, normotensive Wistar Kyoto rats. 
to influence sodium excretion via both arteriolar vasoconstriction and alterations in tubular sodium reabsorption (12-14), we hypothesized that renal denervation altered the development of hypertension in the SHR in part through an effect on renal sodium handling. Therefore, the purpose of these experiments was to determine whether renal sympathetic activity contributes to the development and maintenance of hypertension in the SHR by causing enhanced sodium retention.

\section{METHODS}

Animals used in this study were obtained from Charles River Breeding Laboratories, Wilmington, Mass. Throughout the study they were housed in a room that had constant temperature $\left(24^{\circ} \pm 1^{\circ} \mathrm{C}\right)$ and humidity $(60 \pm 5 \%)$ and was lighted automatically from 6 a.m. to 6 p.m. Systolic blood pressures were measured in conscious restrained rats using an electrosphygmomanometer and physiograph recorder (Narco Bio-Systems, Inc., Houston, Tex.).

To examine the effects of renal denervation during the developmental phase of hypertension, a total of 36 male SHR were subjected to bilateral renal denervation $(n=18)$ or sham operation $(n=18)$ at $7 \mathrm{wk}$ of age. Under ether anesthesia, renal denervation was accomplished through flank incisions by stripping the renal adventitia and painting the renal artery with $20 \%$ phenol (wt/vol) in absolute alcohol. Sham operation consisted of flank incisions only. Blood pressure was monitored twice weekly for $1 \mathrm{wk}$ before and $5 \mathrm{wk}$ after surgery. To assess the effects of renal denervation on sodium excretion in relation to the development of hypertension, a subgroup of renal denervated $(n=8)$ and sham-operated $(n=8)$ rats were housed individually in metabolic cages. These animals remained in the cages for the duration of the study except for brief periods twice weekly when they were removed for blood pressure measurement and weighing. The animals were provided with distilled water and received a purified basal diet (0.29\% sodium) (Ralston Purina Co., St. Louis, Mo.) ad lib. Food and water intake was measured daily. 24-h urine samples for sodium were collected 5 of $7 \mathrm{~d}$. In addition at the end of each 24-h collection period the collection funnel of each cage was rinsed with $50 \mathrm{ml}$ of distilled water and the rinse saved for analysis of sodium content. Sodium concentration (milliequivalents per liter) was measured by flame photometry (model 643; Instrumentation Laboratory, Inc., Lexington, Mass.). Daily sodium excretion was calculated as the product of urine volume and urine sodium concentration plus the product of the wash volume and wash sodium concentration. Daily sodium output was calculated as the fractional excretion of sodium (24-h urinary sodium excretion divided by 24 -h sodium intake $\times 100$ ). Sodium data were expressed as the mean weekly sodium excretion for each group, representing the average of the daily values for all animals in the group for a 1-wk period (five 24-h collections).

Two additional control groups were studied. The first of these was included to assess the effects of phenol on blood pressure and renal sodium handling. 7-wk-old male SHR $(n=8)$ had $20 \%$ phenol i.p. applied through flank incisions in amounts equivalent to those used for renal denervation. Blood pressure and sodium excretion were monitored for 2 wk after treatment. Values were compared to those of agematched sham-operated animals. In the final control group, the effects of renal denervation in normotensive WKY were examined. 7-wk-old WKY $(n=5)$ were subjected to renal denervation by the previously described method. Blood pressure and sodium excretion were monitored for $1 \mathrm{wk}$ before and $2 \mathrm{wk}$ after denervation. Postoperative values for sodium excretion and blood pressure were compared with those obtained during the preoperative control period.

Plasma and kidney renin activity and renal norepinephrine content were determined in groups of SHR serially sacrificed at 1,3 , and 6 wk after renal denervation or sham operation performed as previously described at age $7 \mathrm{wk}$. A minimum of six sham and six denervated rats were sacrificed at each time point. Renal norepinephrine content was measured to assess the completeness of denervation and to determine the time-course for reinnervation. Plasma and kidney renin activity were measured to determine whether the effects of denervation on blood pressure and renal sodium excretion were mediated in part via an effect on the renin-angiotensin system. Animals were killed by decapitation without anesthesia. Blood was collected in iced tubes containing EDTA ( $1 \mathrm{mg} / \mathrm{ml}$ ) for determination of creatinine and plasma renin activity. Kidneys were removed and frozen immediately in liquid nitrogen. The right kidney, which is technically more difficult to denervate, was used for determination of renal norepinephrine content; the left, for determination of kidney renin activity. Renal norepinephrine content was measured by a modification of the radioenzymatic assay of Passon and Peuler (15). Kidney renin activity was determined by a modification of the methods of Haas et al. (16) and Boucher et al. (17), and plasma renin activity by radioimmunoassay of generated angiotensin I according to the method of Haber et al. (18).

To determine the effects of renal denervation in animals with established hypertension 18-wk-old male SHR were subjected to renal denervation $(n=8)$ or sham operation $(n=6)$. Animals were housed in individual metabolic cages and blood pressure and urinary sodium excretion monitored for a 2-wk period after surgery using the methods described above.

In the SHR denervation studies sodium and blood pressure data were analyzed using a $t$ test for unpaired data, and data for phenol and WKY control groups analyzed using the paired $t$ test (19). Values were expressed as mean $\pm S E$ and were considered significant if the $P$ was $<0.05$. The rate of development of hypertension in renal denervated and control SHR was compared using a logistic model (20). The expected values and variances for these curves were obtained by the method of statistical differentials (21). Linear regression analysis was used to compare change in blood pressure with renal norepinephrine content (19).

\section{RESULTS}

Table 1 compares blood pressures of renal denervated and control, sham-operated SHR for 5 wk of observation after surgery. In sham-operated animals blood pressure increased significantly from $135 \pm 4.1 \mathrm{~mm} \mathrm{Hg}$ at $7 \mathrm{wk}$ to $163 \pm 4.2 \mathrm{~mm} \mathrm{Hg}(P<0.05)$ at 9 wk of age. In contrast, denervated animals had a delay in the development of hypertension, and by $9 \mathrm{wk}$ of age blood pressure in this group had increased by only $10 \mathrm{~mm} \mathrm{Hg}(132 \pm 3.7-142$ $\pm 2.8 \mathrm{~mm} \mathrm{Hg}, \mathrm{NS}$ ). Blood pressure of denervated rats was significantly less than that of controls for $4 \mathrm{wk}$ after surgery. During the 5th wk of observation, at which time animals were $12 \mathrm{wk}$ of age, there was no significant difference between the two groups $(188 \pm 3.9$, control vs. $176 \pm 4.6 \mathrm{~mm} \mathrm{Hg}$, denervated, NS). Employing the logistic curve as a statistical model, the rate of development of hypertension in the two groups were compared. 
TABLE I

Systolic Blood Pressure for 5 wk after Renal Denervation or Sham Operation of 7-wk-old SHR

\begin{tabular}{lcccccc}
\hline weeks $\ldots \ldots \ldots \ldots \ldots \ldots$ & Control & 1 & 2 & 3 & 4 & 5 \\
\hline Sham $(n=18)$ & $137 \pm 2.4$ & $147 \pm 3.5$ & $163 \pm 3.9$ & $186 \pm 5.3$ & $181 \pm 3.0$ & $188 \pm 3.4$ \\
Denervated $(n=18)$ & $135 \pm 2.0$ & $132 \pm 2.0$ & $142 \pm 2.9$ & $169 \pm 4.0$ & $164 \pm 3.6$ & $176 \pm 4.6$ \\
& NS & $*$ & $\$$ & $\$$ & NS \\
\hline
\end{tabular}

$$
\begin{aligned}
& { }^{*} P<0.005 . \\
& \ddagger P<0.001 . \\
& \$ P<0.05 .
\end{aligned}
$$

Fig. 1 illustrates that subsequent to the delayed rise in blood pressure in renal denervated SHR, they continued to develop hypertension at a slower rate than sham-operated controls. The curves remained different for $4.5 \mathrm{wk}$ after surgery.

Shown in Fig. 2 are the values for blood pressure and mean weekly sodium excretion of renal denervated and sham-operated animals housed in metabolic cages during the study. Blood pressure in these animals followed a similar course to that described for the group as a whole (Table I). Concomitant with the attenuation of hypertension in renal denervated SHR, urinary sodium

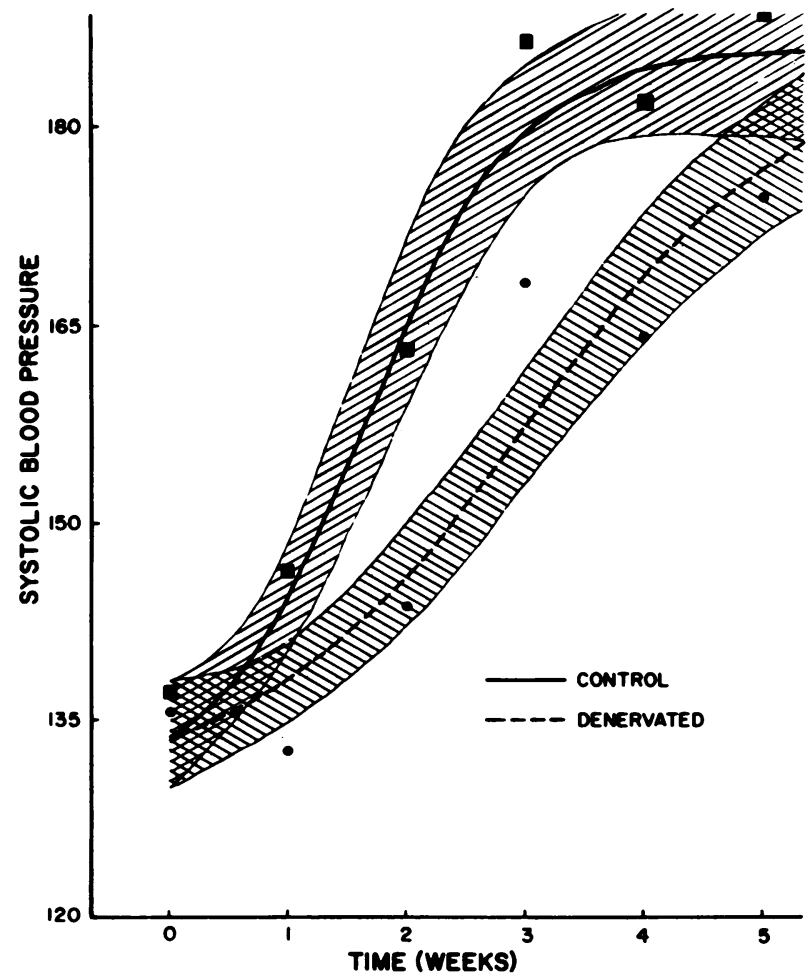

Figure 1 Logistic curves comparing the rate of development of hypertension after renal denervation or sham operation of 7-wk-old SHR. Time zero represents the time of denervation. Asymptotic upper and lower $95 \%$ confidence contours are indicated for each group's curve. excretion was significantly greater than that of shamoperated controls for 3 wk after surgery. As blood pressures of the two groups converged during weeks 4 and 5 , there was no difference in sodium excretion between groups. During the 5-wk period of observation there
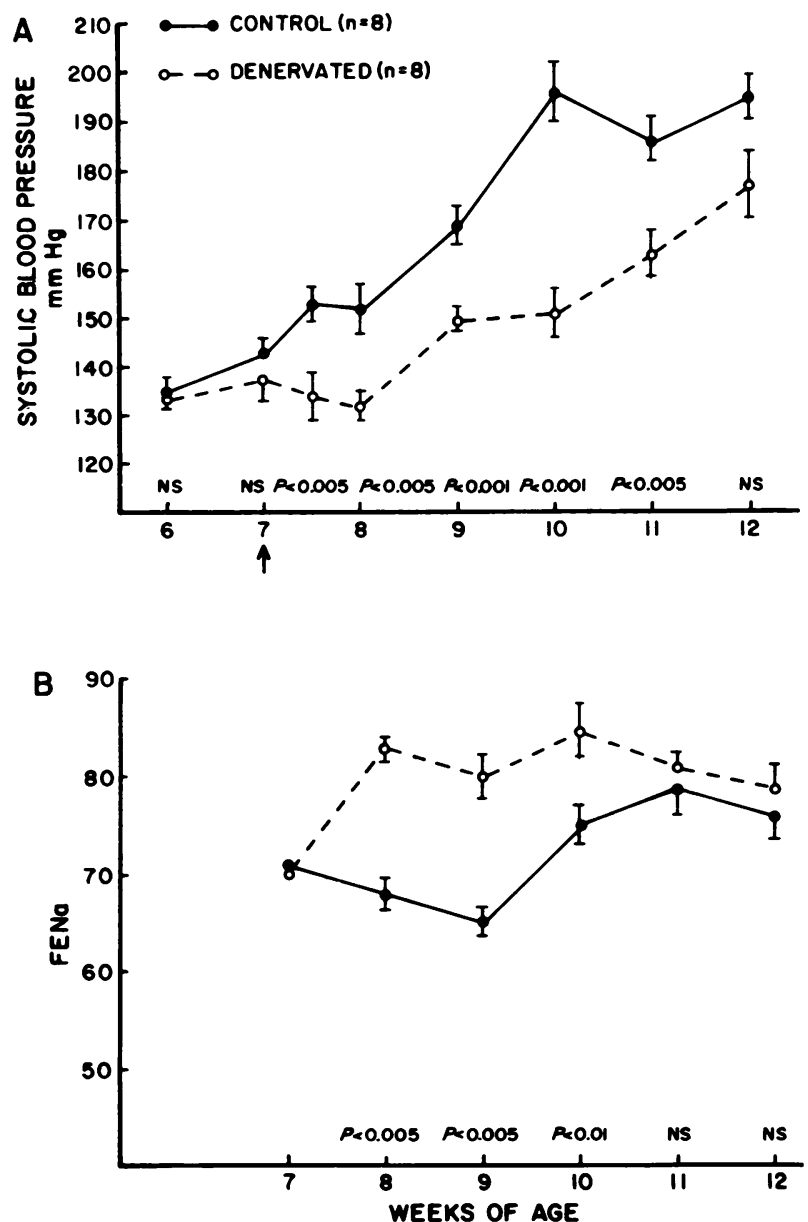

FIGURE 2 (A) Systolic blood pressures of renal denervated and sham-operated animals housed in individual metabolic cages during the study. The arrow indicates time of operation. (B) Corresponding values for mean weekly fractional excretion of sodium (FENa) in the two groups. $P$ values refer to comparisons between groups using $t$ test for unpaired data. 
TABLE II

Effects of Renal Denervation in 7-wk-old SHR on $\mathrm{Na}^{+}$Intake, Water Intake, Urine Volume, and Body Weight. Mean Values* for 5 wk after Renal Denervation or Sham Operation

\begin{tabular}{|c|c|c|c|c|c|c|}
\hline weeks. & & 1 & 2 & 3 & 4 & 5 \\
\hline $\begin{array}{l}\mathrm{Na}^{+} \text {Intake, } \\
\quad m e q\end{array}$ & $\begin{array}{l}\text { Sham }(n=8) \\
\text { Denervated }(n=8)\end{array}$ & $\begin{array}{l}1.54 \pm .09 \\
1.39 \pm .08\end{array}$ & $\begin{array}{l}1.60 \pm .04 \\
1.63 \pm .02\end{array}$ & $\begin{array}{l}1.76 \pm .07 \\
1.68 \pm .08\end{array}$ & $\begin{array}{l}1.63 \pm .04 \\
1.65 \pm .04\end{array}$ & $\begin{array}{l}1.69 \pm .01 \\
1.70 \pm .01\end{array}$ \\
\hline $\begin{array}{l}\mathrm{H}_{2} \mathrm{O} \text { intake, } \\
\quad m l\end{array}$ & $\begin{array}{l}\text { Sham } \\
\text { Denervated }\end{array}$ & $\begin{array}{l}11.0 \pm 1.4 \\
10.9 \pm .68\end{array}$ & $\begin{array}{l}11.8 \pm .60 \\
12.7 \pm .83\end{array}$ & $\begin{array}{l}10.2 \pm .71 \\
12.1 \pm .94\end{array}$ & $\begin{array}{l}12.9 \pm 1.4 \\
14.0 \pm 1.2\end{array}$ & $\begin{array}{l}17.9 \pm .40 \\
18.5 \pm .57\end{array}$ \\
\hline $\begin{array}{l}\text { Urine volume, } \\
\qquad m l\end{array}$ & $\begin{array}{l}\text { Sham } \\
\text { Denervated }\end{array}$ & $\begin{array}{l}2.5 \pm .36 \\
3.0 \pm .86\end{array}$ & $\begin{array}{c}2.5 \pm .22 \\
\ddagger \\
4.0 \pm .40\end{array}$ & $3.5 \pm .56$ & $\begin{array}{l}4.4 \pm .72 \\
4.4 \pm .74\end{array}$ & $\begin{array}{l}6.5 \pm 1.0 \\
7.1 \pm .66\end{array}$ \\
\hline $\begin{array}{l}\text { Body wt } \\
g\end{array}$ & $\begin{array}{l}\text { Sham } \\
\text { Denervated }\end{array}$ & $\begin{array}{l}170 \pm 2.5 \\
161 \pm 3.4\end{array}$ & $\begin{array}{c}204 \pm 2.5 \\
\ddagger \\
193 \pm 4.0\end{array}$ & $212 \pm 2.4$ & $228 \pm 3.0$ & $\begin{array}{l}243 \pm 2.5 \\
242 \pm 4.4\end{array}$ \\
\hline
\end{tabular}

* Mean weekly values for daily intake or excretion.

$\ddagger P<0.05$ (unpaired $t$ test).

were no differences between groups in sodium or water intake (Table II). Urine volume was significantly greater in denervated animals in the 2 nd wk after surgery but was the same in both groups throughout the remainder of the observation period. Plasma creatinine $(0.84 \pm 0.04$, control vs. $0.84 \pm 0.02 \mathrm{mg} / \mathrm{dl}$, denervated) and kidney weight $(0.82 \pm 0.02$, control vs. $0.86 \pm 0.06 \mathrm{~g}$, denervated) were not different at the time of sacrifice.

Table III shows the blood pressure and urinary sodium excretion following treatment with intraperitoneal phenol $(n=6)$. Values did not differ from those of control animals $(n=8)$ that received flank incisions only. This rules out the possibility that the delayed rise in blood pressure and the natriuresis seen after renal denervation were due to a nonspecific systemic or nephrotoxic effect of phenol.

Renal denervation in WKY $(n=5)$ showed that interruption of renal sympathetic nerves does not signifi-

TABLE III

Effects of Intraperitoneal Phenol on Blood Pressure and $\mathrm{Na}^{+}$Excretion in 7-wk-old SHR

\begin{tabular}{lll}
\hline Week 1 & Week 2 \\
\hline \multicolumn{3}{c}{$m m H_{g}$}
\end{tabular}

\begin{tabular}{|c|c|c|}
\hline \multicolumn{3}{|l|}{ Blood pressure } \\
\hline Sham $(n=8)$ & $152 \pm 4.0$ & $168 \pm 3.2$ \\
\hline Phenol $(n=6)$ & $\begin{array}{l}151 \pm 7.1 \\
\text { NS }\end{array}$ & $\begin{array}{l}162 \pm 5.2 \\
\text { NS }\end{array}$ \\
\hline $\begin{array}{l}\text { Fractional excretion } \\
\text { of } \mathrm{Na}^{+}\end{array}$ & & \\
\hline Sham & $65 \pm 1.3$ & $75 \pm 2.1$ \\
\hline Phenol & $\begin{array}{l}63 \pm 1.3 \\
\text { NS }\end{array}$ & $\begin{array}{c}70 \pm 1.2 \\
\mathrm{NS}\end{array}$ \\
\hline
\end{tabular}

cantly alter blood pressure or urinary sodium excretion in normotensive rats (Table IV).

Shown in Fig. 3 are values for plasma and kidney renin activity at 1,3 , and 6 wk after renal denervation or sham operation. No significant difference in plasma renin activity was seen at any time point studied, or in kidney renin activity at 1 and $3 \mathrm{wk}$. A small but statistically significant decrease in kidney renin activity was seen in denervated animals at $6 \mathrm{wk}$. These data indicate that the delayed development of hypertension after renal denervation was not due to suppression of the renin-angiotensin system.

Renal norepinephrine content of denervated and sham-operated animals sacrificed at 1,3 , and $6 \mathrm{wk}$ after surgery is shown in Fig. 4. At 1 wk there was $94 \%$ depletion of norepinephrine content in renal denervated animals, confirming the adequacy of denervation. By $3 \mathrm{wk}$ after surgery renal norepinephrine content of denervated animals had reached $23 \%$ of control values; by $6 \mathrm{wk}, 57 \%$ of control. Although renal norepinephrine content in the denervated group increased sevenfold from week 1 to week 6 after denervation, it remained significantly less than control at week 6 . There was a significant positive correlation between absolute change in blood pressure from the time of surgery until the time of sacrifice and renal norepinephrine content in denervated animals $(r=0.80 ; P<0.0001$ [Fig. 5]).

In SHR subjected to renal denervation at $18 \mathrm{wk}$ of age there was a small, insignificant decrease in systolic blood pressure $1 \mathrm{wk}$ after treatment $(184 \pm 4$. 1 before $\mathrm{vs.}$ $173 \pm 1.3 \mathrm{~mm} \mathrm{Hg} 1 \mathrm{wk}$ after surgery, NS). Blood pressure returned to the preoperative level by $10 \mathrm{~d}$ after surgery. Blood pressures of renal denervated animals were not significantly different from those of sham-operated 
TABLE IV

Effects of Denervation on Blood Pressure and $\mathrm{Na}^{+}$ Excretion in 7-wk-old WKY

\begin{tabular}{lccc}
\hline & Control & Week 1 & Week 2 \\
\hline $\begin{array}{l}\text { Systolic blood pressure, } \\
\quad m m \mathrm{Hg}\end{array}$ & $124 \pm 6.7$ & $115 \pm 5.2^{*}$ & $131 \pm 5.4^{*}$ \\
$\begin{array}{l}\text { Fractional excretion of } \\
\text { sodium }\end{array}$ & $83 \pm 4.2$ & $86 \pm 4.5^{*}$ & $90 \pm 4.6^{*}$ \\
\hline
\end{tabular}

${ }^{*}$ Not significantly different from control (paired $t$ test).

rats for 2 wk after surgery. Renal denervation did not alter the fractional excretion of sodium in 18-wk-old SHR and no differences between groups were demonstrable at one $(82 \pm 2.3$, control vs. $86 \pm 3.0 \%$, denervated, NS) or $2 \mathrm{wk}(78 \pm 1.3$, control vs. $79 \pm 2.7 \%$, denervated, NS) after surgery.

\section{DISCUSSION}

These experiments provide further evidence for an important role of the sympathetic nervous system and, in
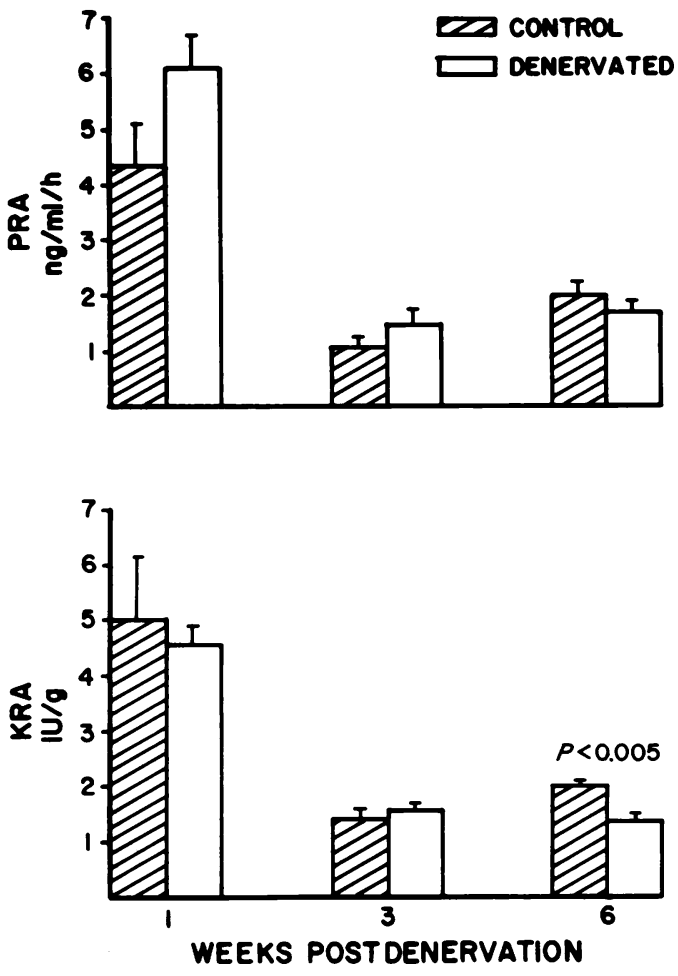

FIGURE 3 Plasma renin activity (PRA) and kidney renin activity (KRA) of SHR killed at 1, 3, and 6 wk after renal denervation or sham operation at $7 \mathrm{wk}$ of age. A minimum of six animals in each group were killed at each time point: The $P$ value refers to the difference between groups using $t$ test for unpaired data. Values for KRA and PRA at 3 and 6 wk were significantly less than those at $1 \mathrm{wk}$ in both groups.

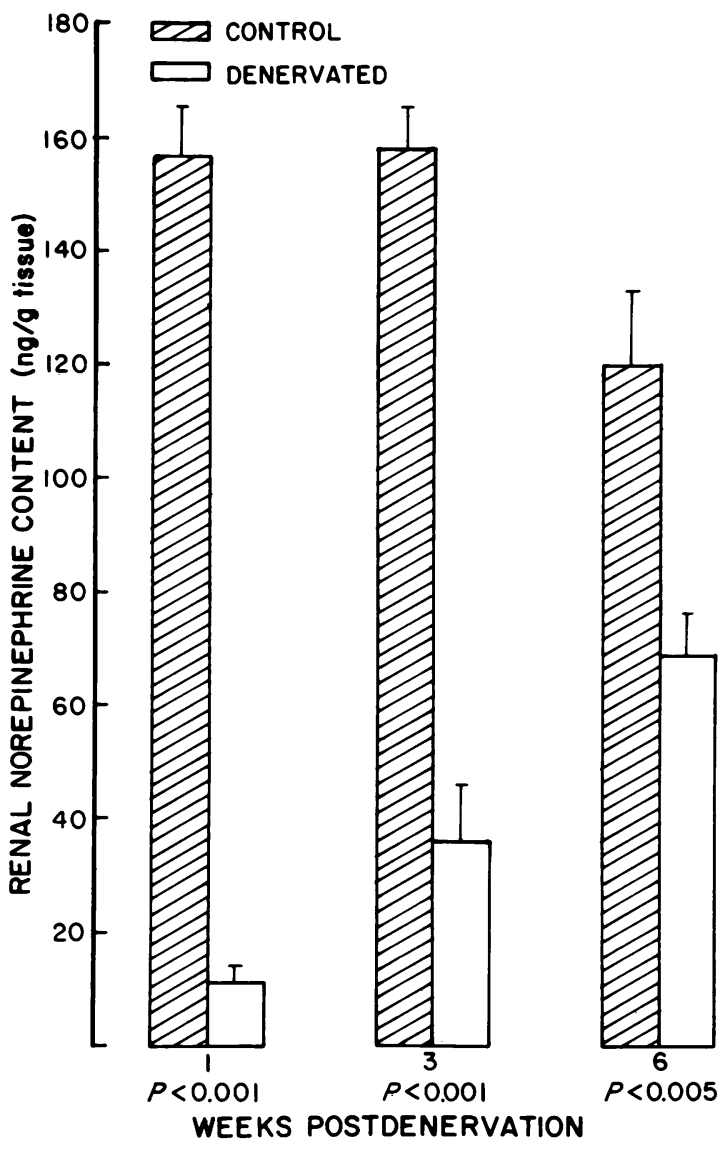

FIGURE 4 Renal norepinephrine content of SHR sacrificed at 1,3 , and 6 wk after renal denervation or sham operation at 7 wk of age. A minimum of six animals in each group were killed at each time point. $P$ values refer to comparisons between groups using $t$ test for unpaired data.

particular, the renal sympathetic nerves in the pathogenesis of hypertension in the SHR. The finding that renal denervation delayed the onset and slowed the rate of development of hypertension in young animals is consistent with earlier investigations that showed similar effects on blood pressure but failed to explain the mechanism(s) involved (9-11). Our observation that the attenuation of the development of hypertension was associated with a significant ir icrease in sodium excretion in renal denervated rats suggests that intact renal sympathetic nerves in the SHR facilitate sodium retention, contributing to the development of hypertension.

In contrast to the findings in the SHR, renal denervation in 7-wk-old WKY produced no change in blood pressure or renal sodium excretion. This observation is in agreement with previous studies demonstrating that the influence of the renal nerves in the long-term regulation of salt and water balance is negligible in conscious normotensive animals under basal conditions $(22$, 


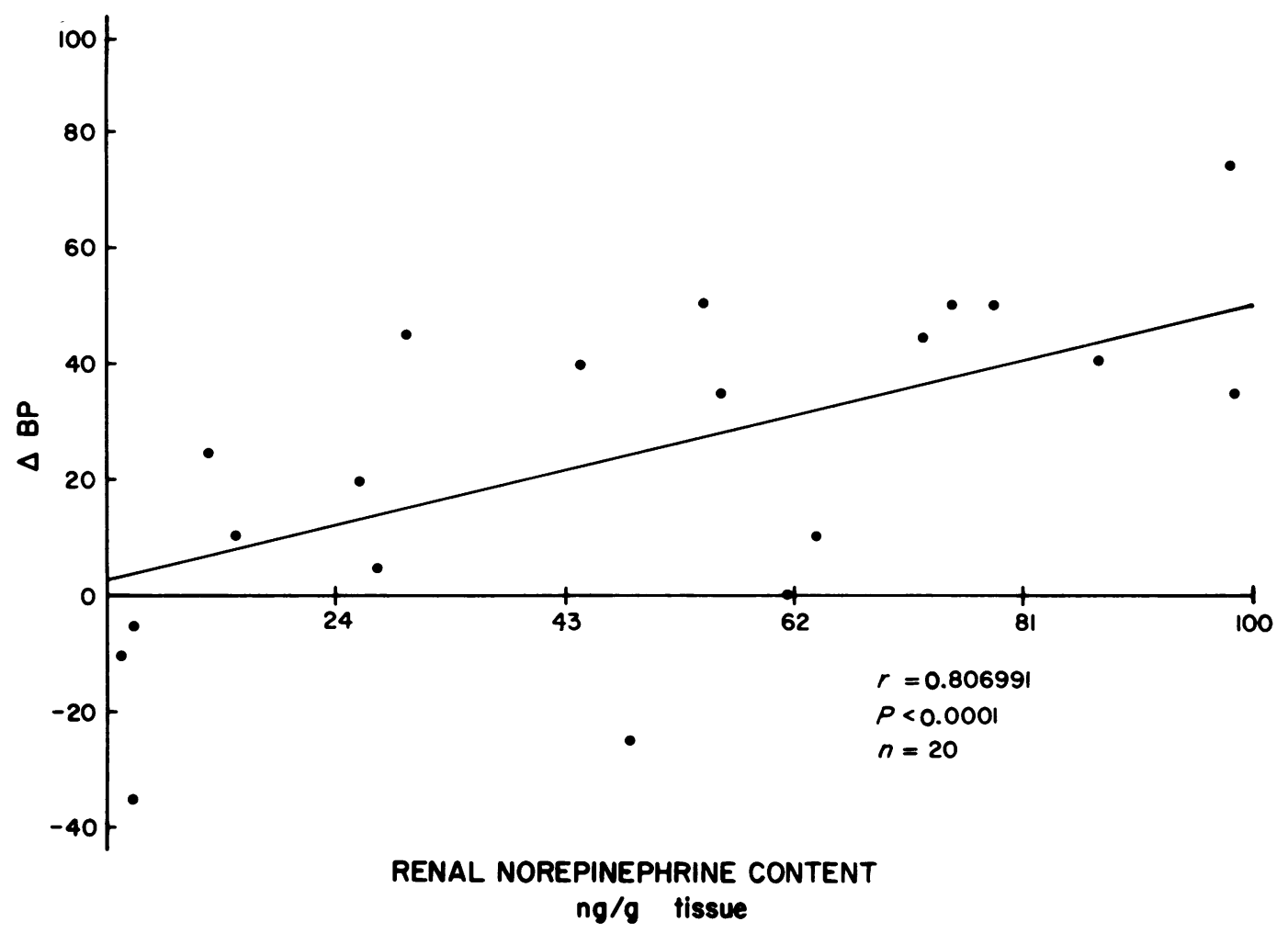

FIGURE 5 Regression analysis comparing the absolute change in blood pressure (BP, at the time of death minus control) with renal norepinephrine content of renal denervated animals.

23). However, in states of increased sympathetic activity, such as during general anesthesia, interruption of renal sympathetic nerves has been shown to produce a natriuresis (24). This evidence, taken together with our finding that renal denervation increases sodium excretion in the SHR, suggests that renal sympathetic activity is increased during the developmental phase of hypertension in this model. This postulate is further supported by the findings of Thoren and Ricksten (8) and Judy et al. (2) that renal nerve traffic in young SHR is significantly increased in comparison to age-matched WKY controls.

The finding that both plasma and kidney renin activity were similar in denervated and sham-operated rats indicates that the effects of renal denervation on blood pressure and sodium excretion in the young SHR did not result from suppression of the renin-angiotensin system. In contrast to our results, previous studies have shown that interruption of the renal sympathetic nerves in normotensive rats was associated with decreased renin stores in the kidney $(25,26)$. Renal denervation in the dog has been shown to decrease renin release under a variety of experimental conditions (27-29). The lack of an observed decrease in plasma and kidney renin activity after renal denervation in the current study could be explained by a tendency of the natriure- sis and presumed attendant decrease in intravascular volume to oppose the effects of denervation. In addition, the lower blood pressure in renal denervated rats would favor an increase in renin synthesis and release mediated via intrarenal baroreceptor mechanisms $(30$, 31 ), further opposing any decrease effected by denervation. The decrements in plasma and renal renin activity seen with age in sham-treated animals are compatible with the results of other investigators (32). The mechanism of this age-related decrement in renin in the SHR is not clearly understood, but may relate to the development of fixed systemic hypertension, to decreased sympathetic activity or to alterations in sodium status.

Although interruption of the renal sympathetic nerves delayed the onset and slowed the rise in blood pressure in the SHR, it did not prevent the ultimate development of hypertension. Our evidence suggests that the eventual development of hypertension in denervated animals may in part be explained by reinnervation. This interpretation is supported by the demonstration of a highly significant positive correlation between the absolute change in blood pressure and renal norepinephrine content of animals sacrificed at intervals after denervation. There was a fourfold increase in renal norepinephrine content from the 1st to the 3rd wk after denervation. Corresponding to this in- 
crease was a significant rise in blood pressure during the 3rd wk. Renal norepinephrine content was further increased at $6 \mathrm{wk}$, but remained significantly depleted in comparison to that of sham-operated animals. Failure of renal norepinephrine content to return to control levels during the 6 -wk period after surgery does not rule out the possibility that reinnervation may have contributed to the ultimate increase in blood pressure after renal denervation. There is experimental evidence to suggest that after denervation return of functional activity precedes complete regrowth of nerve fibers. For example, functional activity of the rat heart, as assessed by the chronotropic response to tyramine, has been shown to approach control levels $2 \mathrm{wk}$ after sympathectomy with 6-OH-dopamine (33). The return of functional activity occurred at a time when myocardial catecholamine stores, which parallel regrowth of nerve fibers, were still $80 \%$ depleted.

The observation that the attenuation of hypertension in SHR subjected to renal sympathectomy was associated with a significant increase in urinary sodium excretion in comparison to sham animals suggests that sodium retention contributes to the development of hypertension in the SHR. However, both groups of animals were in positive sodium balance during the 5 -wk observation period after surgery. Furthermore, Dietz and colleagues (11) have shown that even severe sodium restriction $(<1 \mathrm{mmol} / \mathrm{kg}$ chow) attenuates but does not prevent the development of hypertension in the stroke-prone SHR. Together, these observations suggest that the delayed rise in blood pressure effected by renal denervation in the SHR may not be completely explained by neurally mediated changes in renal sodium handling. The possibility that interruption of renal afferents may influence the development of hypertension is one important consideration. Fernandez et al. (34) have shown that renal denervation increases the norepinephrine content of the hypothalamus in normotensive rats without altering blood pressure (34). This finding was thought by the authors to be secondary to a decrease in plasma renin activity after denervation, but a direct feedback mechanism involving the afferent sympathetic nerves cannot be excluded. The relationship of the renal afferent nerves to the development of hypertension in the SHR merits further examination.

Although renal denervation significantly altered blood pressure and sodium excretion in 7-wk-old SHR, similar changes were not observed after sympathectomy in older animals, indicating that the renal nerves are not important in the maintenance of established hypertension in the SHR. One possible explanation for the failure of renal denervation to decrease blood pressure in older animals may be found in the observation that structural changes both in the renal vascular (35) and other peripheral vascular $(36,37)$ beds have been shown to occur early in the development of hypertension in the SHR and to progress with age (37). These changes effect increases in both renal vascular and total systemic resistance that cannot be reversed by denervation.

In summary, these data provide additional evidence for the participation of the sympathetic nervous system in the development of hypertension in the SHR. This effect appears to be, in part, due to enhanced sodium retention mediated via the renal sympathetic nerves. Once hypertension is established, the renal nerves do not play a significant role in the maintenance of increased blood pressure.

\section{ACKNOWLEDGMENTS}

The authors thank Ms. Terry Koerner, Mr. Braxton Bowdoin, and Mr. Johnnie Wells for their excellent technical assistance; Dr. Charles Katholi for his aid in statistical analysis of the data; and Ms. Joan Chisholm for her help in preparation of the manuscript.

This work was supported by the American Heart Association, Alabama Affiliate (790018) and by National Institutes of Health grants HL 24,420 and HL 23,201.

\section{REFERENCES}

1. Okamoto, K., S. Nosaka, Y. Yamori, and M. Matsumoto. 1967. Participation of neural factors in the pathogenesis of hypertension in the spontaneously hypertensive rat. Jpn. Heart J. 8: 168-180.

2. Judy, W. V., A. M. Watanabe, D. P. Henry, H. R. Besch, W. R. Murphy, and G. M. Hockel. 1976. Sympathetic nerve activity: role in regulation of blood pressure in the spontaneously hypertensive rat. Circ. Res. 38(Suppl. 2): 21-29.

3. Iriuchjima, J. 1975. Sympathetic discharge rate in SHR. In The Nervous System and Arterial Hypertension. S. Julius and M. D. Esler, editors. Charles C Thomas, Springfield, Ill. 51-59.

4. Saavedra, J. M., H. Grobecker, and J. Axelrod. 1978. Changes in central catecholaminergic neurons in the spontaneously (genetic) hypertensive rat. Circ. Res. 42: $529-534$

5. Wijnen, H. J. L. M., D. H. G. Versteeg, M. Palkovits, and W. DeJong. 1977. Increased adrenaline content of individual nuclei of the hypothalamus and the medulla oblongata of genetically hypertensive rats. Brain Res. 135: $180-185$.

6. Haeusler, G., L. Finch, and H. Thoenen. 1972. Central adrenergic neurones and the initiation and development of experimental hypertension. Experientia (Basel). 28: $1200-1203$.

7. Oparil, S., L. Erinoff, and A. Cutilletta. 1976. Catecholamines, blood pressure, renin and myocardial function in the spontaneously hypertensive rat. Clin. Sci. Mol. Med. 51: $455 \mathrm{~s}-459 \mathrm{~s}$.

8. Thoren, P., and S. E. Ricksten. 1979. Recordings of renal and splanchnic sympathetic nervous activity in normotensive and spontaneously hypertensive rats. Clin. Sci. 57: 197s-199s.

9. Liard, J. F. 1977. Renal denervation delays blood pressure increase in the spontaneously hypertensive rat. Experientia (Basel). 33: 339-340.

10. Kline, R. L., P. M. Kelton, and P. F. Mercer. 1978. Effect 
of renal denervation on the development of hypertension in spontaneously hypertensive rats. Can. J. Physiol. Pharmacol. 56: 818-822.

11. Dietz, R., A. Schomig, H. Haebara, J. F. E. Mann, W. Rascher, J. B. Luth, N. Grunherz, and F. Gross. 1978. Studies on the pathogenesis of spontaneous hypertension in rats. Circ. Res. 43(Suppl. 1): 98-106.

12. DiBona, G. R. 1974. Neural control of renal tubular sodium reabsorption in the dog. Fed. Proc. 37: 1214-1217.

13. Prosnitz, E. H., and G. F. DiBona. 1978. Effect of decreased renal sympathetic nerve activity on renal tubular sodium reabsorption. Am. J. Physiol. 235: F557-F563.

14. Schrier, R. W. 1974. Effects of adrenergic nervous system and catecholamines on systemic and renal hemodynamics, sodium and water excretion and renin secretion. Kidney Int. 6: 291-306.

15. Peuler, J. D., and G. A. Johnson. 1977. Simultaneous single radioenzymatic assay of plasma norepinephrine, epinephrine and dopamine. Life Sci. 21: 625-636.

16. Haas, E., H. Lanfrom, and H. Goldblatt. 1954. A simple method for the extraction and partial purification of renin. Arch. Biochem. Biophys. 48: 256-260.

17. Boucher, R. J., J. Menard, and J. Genest. 1967. A micromethod for measurement of renin in the plasma and kidney of rats. Can. J. Physiol. Pharmacol. 45: 881-890.

18. Haber, E., T. Koerner, L. B. Page, B. Kliman, and A. Purnode. 1969. Application of a radioimmunoassay for angiotensin I to the physiologic measurements of plasma renin activity in normal human subjects: Renin activity by angiotensin I radioimmunoassay. J. Clin. Endocrinol. Metab. 29: 1349-1355.

19. Snedecor, G. W., and W. G. Cochran. 1967. Statistical Methods. Iowa State University Press, Ames, Iowa. 6th Edition.

20. Draper, N., and H. Smith. 1966. Applied Regression Analysis. John Wiley \& Sons, New York.

21. Kendall, M., and A. Stuart. 1977. The Advanced Theory of Statistics. Macmillan, Inc., New York. I: 246.

22. Berne, R. M. 1952. Hemodynamics and sodium excretion of denervated kidney in anesthetized and unanesthetized dog. Am. J. Physiol. 171: 148-158.

23. Bricker, N. S., R. A. Straffon, E. P. Mahoney, and J. P. Merrill. 1958. The functional capacity of the kidney denervated by autotransplantation in the dog. J. Clin. Invest. 37: 185-193.

24. DeWardener, H. E. 1973. The control of sodium excretion. In Handbook of Physiology: Renal Physiology. J. Orloff,
R. W. Berliner, and S. R. Geiger, editors. American Physiological Society, Washington, D. C. 695.

25. Taquini, A. C., P. Blaquier, and A. C. Taquini, Jr. 1964. On the production and role of renin. Can. Med. Assoc.J. 90: $210-213$.

26. Tobian, L. M. Braden, and J. Maney. 1964. The effect of unilateral renal denervation on the secretion of renin. $J$. Lab. Clin. Med. 64: 1011. (Abstr.)

27. Mogil, R. A., H. D. Itskovitz, J. H. Russell, and J. J. Murphy. 1969. Renal innervation and renin activity in salt metabolism and hypertension. Am. J. Physiol. 216: 693-697.

28. Grandjean, B., G. Annat, M. Vincent, and J. Sassard. 1978. Influence of renal nerves on renin secretion in the conscious dog. Pfluegers Arch. Eur. J. Physiol. 373: $161-165$.

29. Thames, M. D., and G. F. DiBona. 1979. Renal nerves modulate the secretion of renin mediated by non-renal mechanisms. Circ. Res. 44: 645-652.

30. Tobian, L., A. Tomboulian, and J. Janecek. 1959. The effect of high perfusion pressures on the granulation of juxtaglomerular cells in an isolated kidney.J. Clin. Invest. 38: 605-610.

31. Vander, A. J. 1967. Control of renin release. Physiol. Rev. 47: 359-382.

32. Sen, S., R. R. Smeby, and F. M. Bumpus. Renin in rats with spontaneous hypertension. Circ. Res. 31: 876-880.

33. Nadeau, R. A., J. DeChamplain, and G. M. Tremblay. 1971. Supersensitivity of the isolated rat heart after chemical sympathectomy with 6-hydroxydopamine. Can. J. Physiol. Pharmacol. 49: 36-44.

34. Fernandez, B. E., A. E. Dominguez, N. A. Vidal, and A. C. Taquini, Jr. 1974. Renal denervation and catecholamines of the central nervous system. Neuroendocrinology. 15: 338-345.

35. Folkow, B., M. Hallback, Y. Lundgren, and L. Weiss. 1971. Renal vascular resistance in spontaneously hypertensive rats. Acta Physiol. Scand. 83: 96-105.

36. Folkow, B., M. Hallback, Y. Lundgren, and L. Weiss. 1970. Structurally based increase of flow resistance in spontaneously hypertensive rats. Acta Physiol. Scand. 79: 373-378.

37. Warsaw, D. M., M. J. Mulvany, and W. Halpern. 1979. Mechanical and morphological properties of arterial resistance vessels in young and old spontaneously hypertensive rats. Circ. Res. 45: 250-259. 